\title{
Glutamate Receptor Subunits are Altered in Forebrain and Cerebellum in Rats Chronically Exposed to the NMDA Receptor Antagonist Phencyclidine
}

\author{
Josette S Lindahl*,' and Joyce Keifer ${ }^{2}$ \\ 'Department of Psychiatry, University of South Dakota School of Medicine, Vermillion, SD, USA; ${ }^{2}$ Neuroscience Group, Division of Basic \\ Biomedical Sciences, University of South Dakota School of Medicine, Vermillion, SD, USA
}

\begin{abstract}
Phencyclidine (PCP) is a noncompetitive antagonist of the N-methyl-D-aspartate (NMDA) glutamate receptor subtype. It produces transient psychoses in normal individuals and exacerbates psychoses in schizophrenics. When administered to rodents, PCP elicits stereotypic behaviors including unrelenting head swaying, hyperlocomotion, and social withdrawal. In this study, we examined the relative distribution of the NMDA receptor subunits, as well as the subunits of its modulating receptor, $\boldsymbol{\alpha}$-amino-3-hydroxy-5-methyl-4-isoxazole propionate (AMPA) in the forebrain, hippocampus, and cerebellum of rats chronically exposed to PCP. Rats were injected for 30 days with PCP $(10 \mathrm{mg} / \mathrm{kg})$ and age/sex-matched controls were injected for 30 days with saline vehicle. Brain NMDA and AMPA receptor subunit distribution patterns and protein levels were then analyzed by immunocytochemistry and Western blot analysis. Chronic PCPtreated animals showed significant alterations in glutamate receptor subunits, particularly for the NRI, NR2B, NR2C, and NR2D components of the NMDA receptor. AMPA receptor subunits demonstrated few significant changes in subunit availabilities. Western blot analysis largely confirmed the immunocytochemical findings. These results support the conclusion that subunits of the NMDA receptor are selectively altered by chronic PCP antagonism, with minimal to no changes observed in AMPA receptor subunits. Our findings are consistent with the interpretation that a dysfunctional NMDA receptor complex may mediate abnormal glutamatergic neurotransmission and potentially contribute to the complex etiology of cognitive disorders.

Neuropsychopharmacology (2004) 29, 2065-2073, advance online publication, I 2 May 2004; doi: I 0. I 038/sj.npp. I 300485
\end{abstract}

Keywords: AMPA; schizophrenia; glutamate receptors; psychosis; immunocytochemistry; Western blots

\section{INTRODUCTION}

Clinicians have long noted that phencyclidine (PCP), a lipid soluble, dissociative anesthetic and illicit street drug also known as 'angel dust', produces transient psychoses in normal individuals and exacerbates psychoses in schizophrenics (Javitt and Zukin, 1991). PCP is a noncompetitive antagonist of the $N$-methyl-D-aspartate (NMDA) glutamate receptor that reportedly disrupts glutamatergic neurotransmission via intraionophore blockade (Olney and Farber, 1995). Since neurons bearing NMDA receptors activate inhibitory neurons responsible for regulating excitatory circuits, NMDA receptor antagonism is thought to result in

\footnotetext{
*Correspondence: Dr JS Lindahl, Neuroscience Group, Division of Basic Biomedical Sciences, University of South Dakota School of Medicine, Vermillion, SD 57069, USA, Tel: + |-605-677-319|, Fax: + I-605-677-5658, E-mail: jlindah|@usd.edu

Received 07 August 2003; revised 25 March 2004; accepted 13 April 2004

Online publication: I5 April 2004 at http://www.acnp.org/citations/ Npp41503356/default.pdf
}

unmodulated hyperstimulation of these circuits (Lewis and Lieberman, 2000; Duncan et al, 1999; Olney et al, 1999; Hirsch et al, 1997). Theoretically, the net effect of NMDA receptor hypofunction in experimental animal brain is excessive synaptic glutamate release, which subsequently precipitates excitotoxic lesioning (Moghaddam and Adams, 1998; Moghaddam et al, 1997). These lesions appear similar to the structural and histological abnormalities seen in postmortem human schizophrenic brain (Corso et al, 1997; Horwath et al, 1997). Thus, glutamate receptor dysfunction may ultimately underscore the psychotic behaviors characteristic of PCP exposure and more globally, contribute to the multifaceted etiology of schizophrenic-like cognitive disorders.

The NMDA receptor is a heteromeric complex primarily comprised of NR1 subunits, a family of NR2 subunits and NR3 subunits (Kutsuwada et al, 1992; Monyer et al, 1994; Hollman and Heinemann, 1994). The NR1 subunit is obligatory for receptor function, whereas partnering NR2 proteins (NR2A, NR2B, NR2C, NR2D) impart unique physiological characteristics to the NMDA receptor complex 
(Monyer et al, 1994). Recently described NR3 subunits modulate NMDA receptor activity by enhancing excitatory glycine responsiveness (Chatterton et al, 2002). Like the NMDA receptor, the $\alpha$-amino-3-hydroxy-5-methyl-4-isoxazole propionate (AMPA) receptor is also assembled from a variable combination of four subunits termed GluR1-4 (Woodruff and Healy, 2000). Ultimately, receptor diversity is achieved through tissue-specific subunit assembly. Since subunit combinations define the specific functional properties of individual receptors, alterations to heteromeric complex assembly will influence receptor performance (Chazot and Stephenson, 1997; Dunah et al, 1998). The NMDA receptor is a ligand-gated, voltage-sensitive protein complex that is highly permeable to calcium. This glutamatergic receptor is unusual in that it requires cooperative postsynaptic membrane depolarization, most often by colocalized AMPA receptors (Morris and Davis, 1994). Postsynaptic depolarization removes the magnesium block within the NMDA channel, thereby allowing calcium exchange to propagate slow neurotransmission. Functionally, the NMDA and AMPA glutamatergic receptors have been implicated in diverse brain activities, including learning and memory, synaptic plasticity and remodeling, and neuronal development (Huntley et al, 1994).

While completely faithful duplication of human psychiatric experiences in animal models is nearly impossible, rodents exposed to PCP demonstrate stereotypic behaviors that persist to the exclusion of normal activities (Murray and Horita, 1979). Some prominent PCP-induced behavioral abnormalities include unrelenting head swaying, ataxia, extended periods of backward locomotion, hyperlocomotion, hindquarter rolling, digit gnawing, and social isolation. These behaviors typically manifest for 2-3 h following acute exposures, but persist for extended periods $(>12 \mathrm{~h})$ with chronic dosaging $(>21$ days). While others have reported changes in specific NMDA subunit gene transcripts following pharmacological antagonism of the NMDA receptor (Al-Amin et al, 2003; Linden et al, 2001; Oh et al, 2001; Wang et al, 1999; Wilson et al, 1998; Sircar et al, 1996), the regulation of NMDA and AMPA receptor proteins by chronic receptor antagonism has yet to be described. Examining the NMDA glutamate receptor at a level other than transcriptional control merits attention, given the plethora of post-transcriptional and post-translational modification events known to modulate receptor availability, complex assembly, subunit delivery, and membrane insertion. Here, we wished to determine how chronic blockade of the NMDA receptor by a pharmacologic agent used widely as a drug of abuse affects the distribution of NMDA and AMPA subunits at the protein level. We induced sustainable stereotypic behaviors in Sprague-Dawley rats with chronic, daily PCP exposure. Following 30 consecutive days of either the NMDA receptor antagonist or vehicle, brain tissue was removed and prepared for immunocytochemistry or Western blot analysis. Three brain regions were examined: the frontal cortex and the $\mathrm{CA} 3$ region of the hippocampus, both strongly implicated in cognitive function and memory, and the cerebellum, which is primarily responsible for motor coordination, muscle tone, and balance.

\section{METHODS}

\section{Administration of PCP and Brain Tissue Preparation}

Adult male Sprague-Dawley rats $(n=12 ; 200-250$ g; Charles River Laboratories) received daily intraperitoneal injections of PCP $(10 \mathrm{mg} / \mathrm{kg}$, Sigma Chemical, St Louis, MO) in $0.5 \mathrm{ml}$ of $0.9 \%$ saline vehicle for 30 days. This dosage has previously been shown to elicit stereotypic behaviors without producing toxicity (Scalzo and Holson, 1992). Age- and sex-matched control rats received comparable daily injections of saline vehicle. At $12 \mathrm{~h}$ following the final (30th) injection of PCP or vehicle, animals were anesthetized with sodium pentobarbital $(60 \mathrm{mg} / \mathrm{kg})$, transcardially perfused with saline followed by cold $4 \%$ paraformaldehyde at $\mathrm{pH} 7.4$ for the immunocytochemical studies, or decapitated for fresh brain protein extractions. Protocols involving the use of animals complied with the guidelines of the NIH and the Institutional Animal Care and Use Committee.

\section{Immunocytochemistry and Imaging Analysis}

Brain tissues were sliced in the coronal plane at $50 \mu \mathrm{m}$ in series of 10 sections for each of the nine glutamate receptor antibodies tested and one series for thionin $(0.1 \%)$ counterstaining. Immunocytochemistry was performed by the methods of Keifer (2001). Primary antibodies were chosen for their rat species-specific recognition of target peptides by immunohistochemistry and Western blotting techniques. Anti-NR1 (Pharmingen, San Diego, CA; Cat. $60021 \mathrm{~A}$-clone 54.1 ) is a mouse monoclonal antibody that recognizes amino acids 660-811 within the subunit's intracellular loop between transmembrane regions III and IV. Clone 54.1 is specific for the NR1 obligatory subunit. It does not recognize any NR2 partner (Brose et al, 1994; Siegel et al, 1994; Siegel et al, 1995). Anti-NR2A (Chemicon, Temecula, CA; Cat. AB1555P) and Anti-NR2B (Chemicon, Temecula, CA: Cat. AB1557P) are rabbit polyclonal antibodies to C-terminal fusion proteins containing the subunits' amino-acid sequences 1253-391 and 984-104, respectively. Characterization studies have demonstrated no crossreactivity to other NR2 subunit peptides (Brandoli et al, 1998; Khan et al, 1999). Rabbit polyclonal anti-NR2C (Chemicon, Temecula, CA; Cat. AB1592P) recognizes the C-terminal region of the $\mathrm{NR} 2 \mathrm{C}$ peptide. While use in immunohistochemistry is not technically recommended by the manufacturer, this antibody has precedence in the literature for application in neuronal labeling (Yung, 1998). Studies were duplicated using a different polyclonal rabbit anti-NMDAR2C antibody (BD PharMingen, San Diego; Cat. 559891) with similar results. Furthermore, our immunoblots demonstrated a single NR2C protein band of the appropriate molecular size $(\mathrm{mw}=140 \mathrm{kDa})$ without crossreactivity to NR2A or NR2B $(\mathrm{mw}=180 \mathrm{kDa})$. Primary polyclonal antibody to a C-terminal peptide region of the NR2D subunit was raised in goat (Santa Cruz Biotechnology, Santa Cruz, CA; sc-1471). Unfortunately, characterization data is somewhat limited. However, in our hands and in others work (Hollman and Heinemann, 1994; Watanabe et al, 1994; Glover, 2000), this antibody produces a single band that does not appear to crossreact with other NR2 or NR1 
subunits. All primary antibodies to AMPA receptor subunits (GluR1-4) were obtained from Chemicon (Temecula, CA; Cat. AB1504-GluR1, AB1768-25UG-GluR2, AB1506-GlurR2/3, and AB1508-GluR4). Except for the GluR2/3 antibody that recognizes the nearly identical carboxy-terminal sequence of GluR2 and GluR3, all AMPA subunit antibodies have demonstrated minimal to no crossreactivity. These antibodies were generated from unique carboxy-terminal peptide sequences and are recommended for both immunohistochemistry and Western blot applications (Yung, 1998; Osten et al, 1998; SassoePognetto and Ottersen, 2000; Bernard et al, 1996). Given the homology between the GluR2/3 carboxy-termini, antiGluR2 was produced from a synthetic peptide containing 16 unique amino acids conjugated to bovine serum albumin through a cysteine residue incorporated into GluR2's Cterminal region. Optimal concentrations of the primary antibodies were 1:1000 for NR1, NR2B, NR2C, NR2D; $1: 500$ for NR2A; and $1: 100$ for GluR1-4. Triton X-100 $(0.1 \%)$ was added to GluR2/3 and GluR4 antibody cocktails to enhance antibody penetration. Secondary antibodies were a Cy3-conjugated goat anti-mouse IgG, a Cy3conjugated goat anti-rabbit IgG, and a Cy3-conjugated rabbit anti-goat IgG (Jackson ImmunoResearch, West Grove, PA). All secondary antibodies were diluted 1:100. Digital images of immunoreactive tissue sections were taken using epifluorescence on a Zeiss Axioskop microscope equipped with an Axiocam digital camera. Images were then imported for computer-assisted quantitation using Adobe Photoshop software as described by Keifer (2001). Average luminosity level and standard deviation of the pixels in selected fields were calculated. Values were obtained for labeled areas and subtracted from background values taken from unlabeled areas for every section analyzed to control for staining variations. Six separate sections were analyzed and averaged for each case. StatView software was used for statistical analysis using ANOVA to determine significance levels. Immunocytochemistry and image analysis have been used previously to examine whether specific proteins such as glutamate receptors are altered due to experimental manipulation (Keifer, 2001; Keifer et al, 2003). This approach has proven to be valuable in assessing protein changes with high spatial resolution, which can be corroborated by using the more global Western blot analyses. A similar approach has been applied by others (Ouyang et al, 1999). Frontal cortex was analyzed from approximately $2.2 \mathrm{~mm}$ rostral to bregma, to $-0.40 \mathrm{~mm}$ caudal according to Paxinos and Watson (1998) (approximately the level of the striatum). Medial to lateral regions from M2 to S2 for all cortical layers were examined. The cerebellar cortex was analyzed by selecting a uniform sized square of the same magnification for all sections that was centered on the Purkinje cell layer and enclosed equal amounts of the molecular and granule cell layers. Cerebellar regions were randomly selected and averaged. Finally, the pyramidal cell layer of the CA3 region of the hippocampus was analyzed in its entirety.

\section{Western Blot Analysis}

Protein extractions from freshly harvested rat brains were carried out according to the method of Chen et al (1998).
SDS-PAGE was performed to separate individual subunits. Following electrophoretic transfer to Immobilon-P using a semidry transfer apparatus (BioRad, Hercules, CA) membranes were blocked with $5 \%$ nonfat dry milk and incubated in primary and secondary antibodies according to the method of Boesch et al (1996). The same antibodies chosen for immunocytochemistry were used for Western blot, but dilutions were optimized at $1: 100-1: 400$. Host-appropriate HRP-conjugated secondary antibodies were used at $1: 100000$ dilution. Proteins were detected using the ECLPlus chemiluminescence system (Amersham Pharmacia, Piscataway, NJ). Immunoreactive signals were captured on Kodak X-omatic AR film (Eastman Kodak, Rochester, NY) and quantified by computer-assisted densitometry (ChemiImager software). Individual subjects $(n=6$ salinetreated animals; $n=6$ PCP-treated animals) were subjected to triplicate Western blots (three blots per animal per subunit). Following normalization to actin, data were compressed by specific subunits across subjects and subjected to statistical analysis by a paired $t$-test.

\section{RESULTS}

Examination of glutamate receptor subunits from PCPtreated and control rat brains revealed marked differences in immunoreactivity, primarily for NMDA receptor subunits rather than for AMPA receptor subunits. Quantitative analysis of the relative levels of glutamate receptor subunit immunoreactivities by specific brain region was performed on digitized images. As stated earlier, the NR1 subunit is required for NMDA receptor function and, as shown in Figures 1 and 4, immunoreactivity for this subunit was significantly reduced in PCP-treated frontal cortex compared to controls $(\mathrm{F}(1,35)=27.4, p<0.0001$; Figure 1a and $\mathrm{b}$; Figure 4). NR1 immunolabeling of the CA3 region of the hippocampus likewise showed differences between PCPtreated and control brains. As opposed to the decrease in NR1 staining of the frontal cortex, the pyramidal cell layer of CA3 was more intensely immunopositive for NR1 in PCP-treated brain $(\mathrm{F}(1,39)=5.9, p<0.02$; Figure $1 \mathrm{c}$ and $\mathrm{d}$; Figure 4$)$. When the pattern of NR1 immunolabeling in the cerebellar cortex of PCP-treated rat brain was compared with that of control rat brain, no significant differences were found $(\mathrm{F}(1,32)=0.40 ; p=0.55$; Figure 1e and f; Figure 4).

Of the NR2 proteins examined in this study, NR2A was the only subunit that did not show altered expression in either the frontal cortex, the CA3 region of the hippocampus, or the cerebellar cortex (Figure 4). However, NR2B protein detection was significantly reduced in all brain regions studied following chronic NMDA receptor antagonism by PCP (frontal cortex, $\mathrm{F}(1,34)=33.2, p<0001$; CA3 hippocampus, $\mathrm{F}(1,39)=9.4, p<0.003$; cerebellum, $\mathrm{F}(1$, $32)=16.6, p<0.0003$; Figure 2a-f; Figure 4). Similarly, NR2C subunit levels were notably reduced but differences in protein expression were confined to the frontal cortex $(\mathrm{F}(1$, $34)=23.2, p<0.0001)$. Interestingly, the only NR2 subunit upregulated by chronic NMDA receptor antagonism with PCP was NR2D within the frontal cortex $(F(1,28)=22.0$, $p<0.0001$; Figure $3 c$ and $d$; photomicrographs of immunocytochemistry not shown for CA3 hippocampus or cerebellum; Figure 4). 

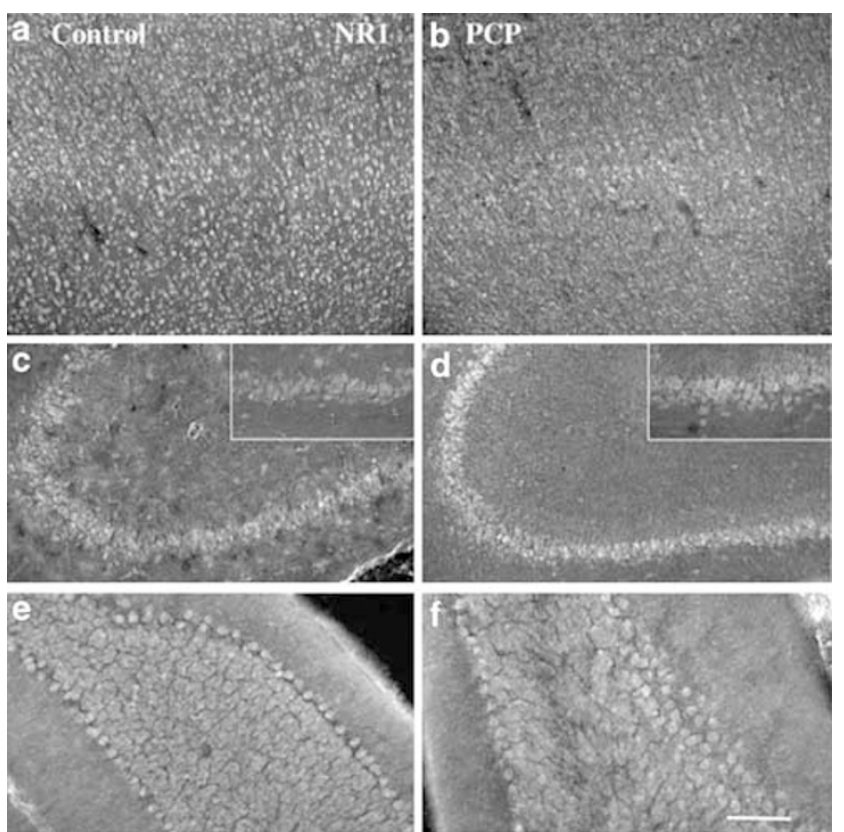

Figure I Photomicrographs of NMDA receptor subunit NRI immunoreactivity from control and PCP-treated rat brains. (A and B) In the frontal cortex, neuronal cell bodies throughout all layers of the cortex were intensely stained for NRI in controls (left panel), whereas NRI immunolabeling is greatly diminished in the PCP-treated subjects (right panel). ( $c$ and d) The pyramidal cell layer of the CA3 region of the hippocampus was more intensely NRI immunopositive in the PCP-treated rats as compared to controls. The insets show a higher magnification of labeled pyramidal neurons. (e and f) In the cerebellum of control subjects, Purkinje cells and the granule cell layer were moderately immunopositive for NRI, whereas the molecular layer was lightly stained to unstained. This labeling appeared to be unchanged in the PCP-treated rats. Scale bar: a-f, $100 \mu \mathrm{m}$.

In striking contrast to the multiple changes in NMDA receptor subunits, immunoreactivity for the AMPA receptor subunits GluR1, GluR2, GluR2/3, and GluR4 in the frontal cortex was not significantly different following chronic PCP treatment (Figure 4). In fact, of the four AMPA subunits examined in three regions of the brain, GluR2 $(\mathrm{F}(1$, $36)=8.8 ; p<0.005)$ and GluR2/3 $(\mathrm{F}(1,38)=5.8, p<0.02)$ in the CA3 region of the hippocampus were the only AMPA proteins altered in association with chronic NMDA receptor antagonism (Figure 4). In both cases, protein levels were increased.

Western blot analyses of NMDA receptor subunits in the frontal cortex and cerebellum largely confirmed the immunocytochemical findings (Figure 5). Specifically, Western blot analysis of the frontal cortex proteins demonstrated significantly decreased levels of both the NR1 subunit and the NR2C subunit in PCP-treated brains compared to control brains. Consistent with the immunocytochemical data, the NR2D subunit was detected in significantly greater quantities in the frontal cortex of PCPexposed animals. As expected, NR2A showed little overall change in any brain region studied. Western blot analysis of cerebellar proteins likewise confirmed no change in NR1 or $\mathrm{NR} 2 \mathrm{~A}$, and an increase in the NR2C subunit from PCPtreated brains (data not shown). Surprisingly, while immunocytochemistry showed a significant decrease in
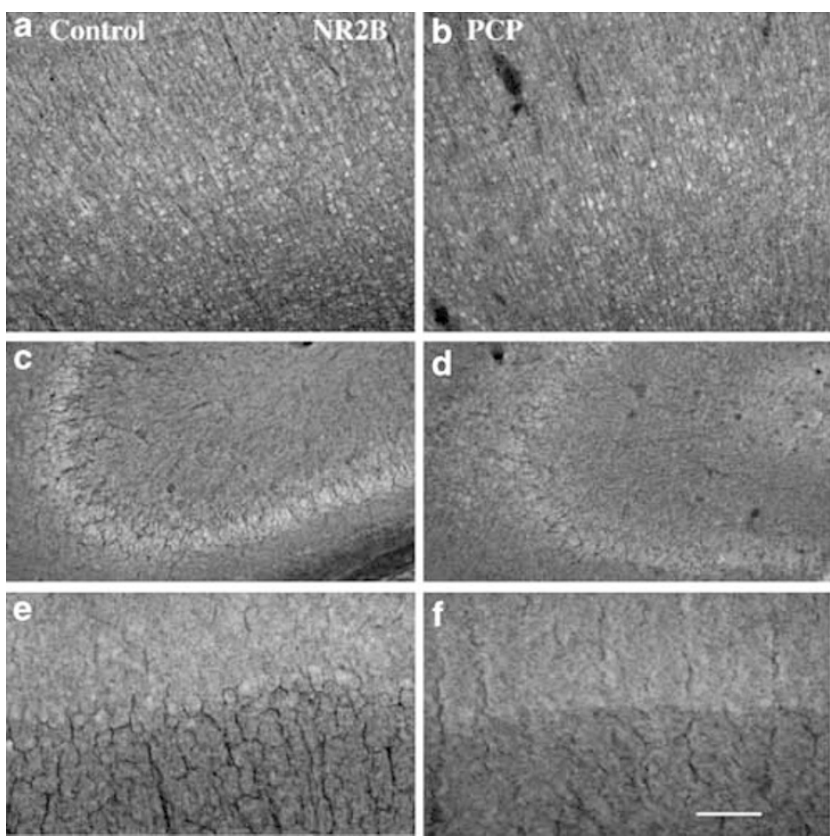

Figure 2 Photomicrographs of NMDA receptor subunit NR2B immunoreactivity from control and PCP-treated rats brains. ( $a$ and b) Numerous neuronal cell bodies were immunopositive for NR2B throughout all layers of the frontal cortex in controls. The intensity of labeling was reduced in PCP-treated subjects. ( $c$ and $d$ ) In the CA3 region of the hippocampus, staining of the pyramidal cell layer was decreased in PCPtreated rats. (e and f) The molecular and granule cell layers of the cerebellar cortex from controls were intensely immunopositive for NR2B, while the Purkinje cells were moderately labeled. PCP treatment resulted in a reduction of label in the molecular layer and of Purkinje cells. Scale bar: $a-f$, $100 \mu \mathrm{m}$.
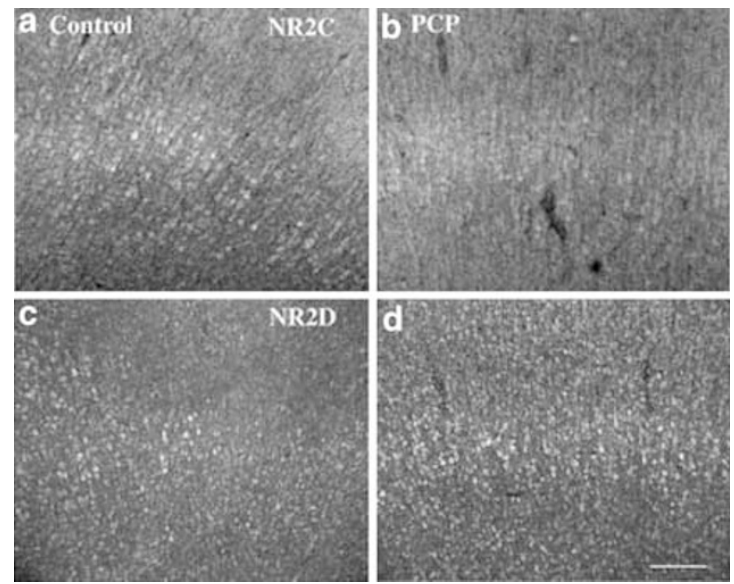

Figure 3 Photomicrographs of immunoreactivity for NR2C and NR2D subunits of the NMDA receptor in the frontal cortex from control and PCP-treated rats. ( $\mathrm{a}$ and $\mathrm{b}$ ) Control rats showed considerable labeling of neurons in the frontal cortex for NR2C, but the label was reduced in PCPtreated rats. ( $c$ and $d$ ) Immunostaining for NR2D clearly showed labeled neurons in the cortex, but the overall amount of label was less than for the other NMDA receptor subunits examined. Following PCP treatment, the number of NR2D immunopositive neurons and intensity of label appeared to be significantly increased in the frontal cortex. Scale bar: a-d, $100 \mu \mathrm{m}$.

NR2B levels in both the frontal cortex and cerebellar cortex, Western blot analysis consistently demonstrated an increase in NR2B subunit levels in both brain regions. 


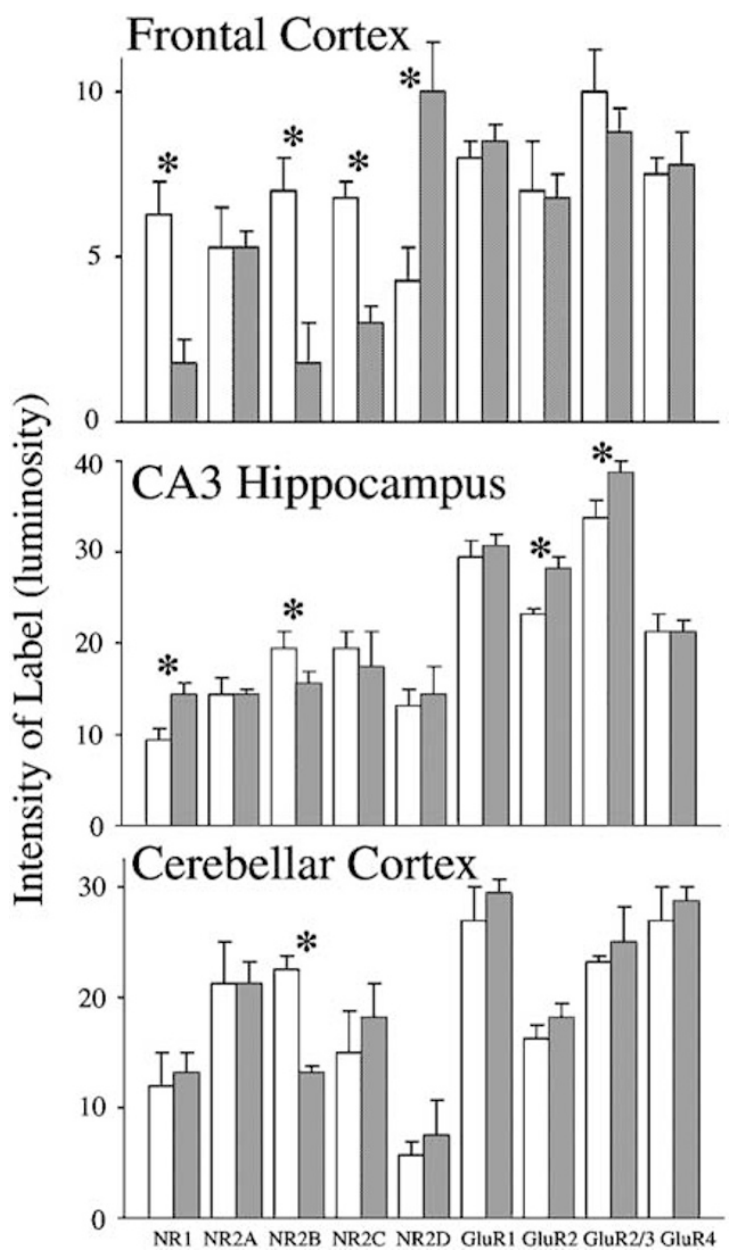

Figure 4 Summary histograms of the immunocytochemical data for all of the glutamate receptor subunits tested in the frontal cortex (a), CA3 region of the hippocampus (b), and the cerebellar cortex (c) for control rats (white bars) and PCP-treated rats (shaded bars). Values plotted on the $y$ axis for the intensity of immunoreactivity are in arbitrary numbers that represent average pixel luminosity. (a) In the frontal cortex of PCP-treated rats, there was a significant decrease in immunoreactivity for NRI $(-20 \%$ of the control), NR2B ( $-49 \%$ of the control), NR2C ( $-35 \%$ of the control), and a significant increase in NR2D ( $+266 \%$ of the control). No changes were observed in the AMPA receptor subunits. (b) The CA3 region of the hippocampus showed a significant increase in NRI $(+168 \%$ of the control) and GluR2 (+ II8\% of the control) and a significant decrease in NR2B $(-77 \%$ of the control) and NR2C $(-72 \%$ of the control). (c) The cerebellar cortex showed a significant decrease in NR2B ( $-59 \%$ of the control) and an increase in GluR2/3 $(+121 \%$ of the control). *Significant differences between control and PCP-injected rats. P-values are given in the text.

\section{DISCUSSION}

\section{NMDA Antagonism and NR Transcripts}

Neuroanatomical and molecular studies documenting alterations in glutamate receptor subunit expression following sustained pharmacological antagonism of the NMDA receptor have primarily focused on gene transcripts. Wang et al (1999) and Oh et al (2001) both noted an increase in NR1 mRNA levels in the frontal cortex of adult rat brain following chronic PCP or MK801 exposure, while no changes were noted in either the hippocampus or cerebellum. Wilson et al (1998) similarly confirmed an over-
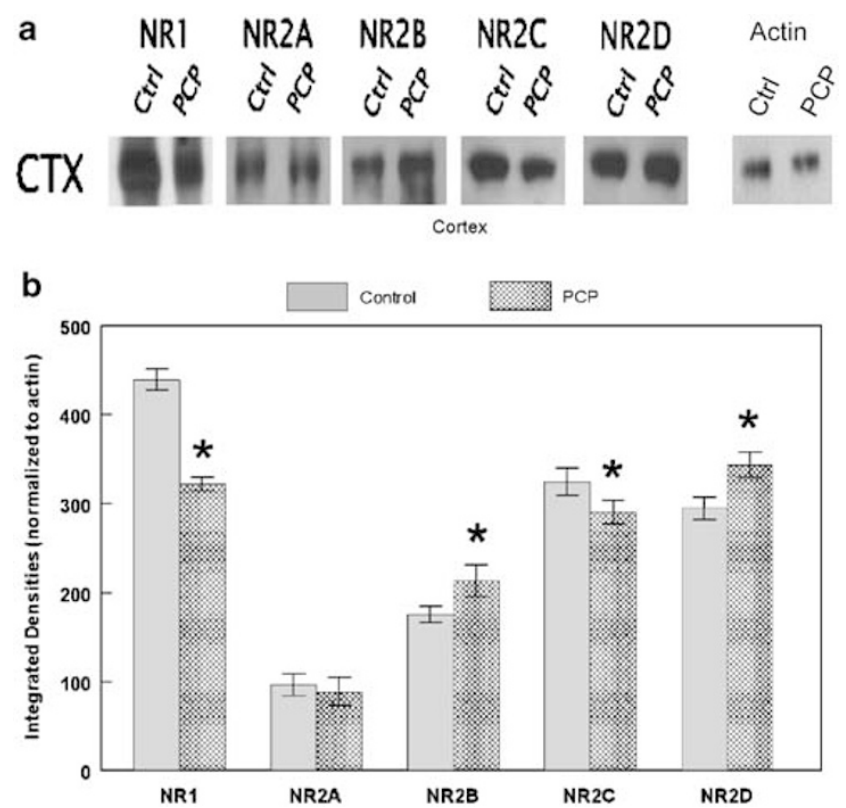

Figure 5 Western blot analysis of the frontal cortex (CTX) from control (Ctrl) and PCP-treated (PCP) rats. Equal amounts of protein from the frontal cortex of the control (saline) or PCP-treated rats were subjected to independent immunoblots for NRI (2 $\mu$ g protein), NR2A ( $0 \mu \mathrm{g}$ protein), NR2B ( $10 \mu \mathrm{g}$ protein), NR2C ( $10 \mu \mathrm{g}$ protein), and NR2D ( $15 \mu \mathrm{g}$ protein) subunits. Actin was independently blotted as a loading control and used to normalize each protein pair (control and PCP treated). (a) In the frontal cortex, immunoblots demonstrate a significant decrease in NRI protein $(\mathrm{mw}=116 \mathrm{kDa})$, no change in NR2A $(\mathrm{mw}=180 \mathrm{kDa})$, an increase in $\mathrm{NR} 2 \mathrm{~B}(\mathrm{mw}=180 \mathrm{kDa})$, a decrease in NR2C $(\mathrm{mw}=140 \mathrm{kDa})$, and an increase in NR2D (mw $=160 \mathrm{kDa})$. (b) Graph of integrated densities normalized to actin loading control. *Statistical significance at the $p<0.05$ level.

abundance of NR1 transcripts in developing neonatal brain after a single, critically timed MK801 dose. Interestingly, Sircar and Chang (1994) and Sircar et al (1996) found no alterations in NR1 mRNA levels in the developing rat frontal cortex or cerebellum following chronic PCP assault, but described a generalized decrease in NMDA receptor density as measured by $\left[{ }^{3} \mathrm{H}\right] \mathrm{MK} 801$-binding studies.

While there is general agreement that NR1 message increases in the frontal cortex following either PCP or MK801 treatment, investigators have yet to reach consensus with regard to consistently reproducible changes in NR2 subunit mRNAs or proteins following drug-specific NMDA receptor antagonism. For example, Oh et al (2001) reported a decrease in NR2A mRNA in cerebellum and an increase in NR2B mRNA in adult rat frontal cortex following chronic infusion of MK801. They noted no change in NR2C message. In contrast, Linden et al (2001) demonstrated an MK801-associated decrease in both NR2B and NR2C mRNA in rat parietal cortex and no PCP-associated changes in any NR2 message. Al-Amin et al (2003) similarly found no alterations in NR2 subunit message from nucleus accumbens, striatum, cingulated, or piriform cortex with chronic MK801 treatment. Frontal cortex was not examined in either study. When examining neonatal rat brain, Sircar et al (1996) reported a decrease in frontal cortex NR2B mRNA after chronic, moderate doses of PCP and no changes in any 
cerebellar NR2 subunits, while Wilson et al (1998) found a predominant increase in NR2A mRNA in the cerebral cortex, striatum, and hippocampus using high doses of single exposure MK801. Thus, mRNA data for NR2 subunit gene expression is inconclusive. Differences may be due to differential expression within unique brain regions or perhaps to the specific experimental parameters applied in each study (ie receptor antagonist, dose, duration, timing).

\section{NMDA Antagonism and NR Proteins}

Studies describing antagonist-induced changes in NMDA receptor subunit expression at the protein level are limited. Hanania et al (1999) demonstrated a PCP-induced increase in NR1 subunit protein in the frontal cortex by immunohistochemistry using a monoclonal antibody that recognizes all NR1 isoforms. Other laboratories have indirectly shown enhanced NMDA receptor complex densities by ligandbinding studies under various conditions of drug-induced NMDA antagonism (Gao and Tamminga, 1994; Williams et al, 1992; McDonald et al, 1990). Sircar et al (1996), however, reported a decrease in NMDA receptor complex densities in the neonatal cortex with prolonged PCP exposure. Effects of NMDA receptor antagonism on NR2 subunits, particularly the NR2D subunit, have not been described until the present study. From previous mRNA and protein studies, it is apparent that pharmacological alterations of the NMDA receptor are antagonist specific, dose and timing sensitive, developmental state dependent, and regionally diverse. This is the first comprehensive study that systematically describes NMDA receptor subunit alterations at the protein level following chronic, prolonged PCP antagonism.

\section{NMDA Receptor mRNA Alterations in Schizophrenia}

Inconsistent and conflicting results are not confined to pharmacological models of schizophrenia. Neuroanatomical studies of NMDA and AMPA receptor subunit compositions from normal and schizophrenic human subjects have also generated highly variable data. Protein-binding studies using either radioactively labeled ligand (Simpson et al, 1992) or antibodies to the NR1 subunit (Chen et al, 1998) have demonstrated an upregulation of NMDA receptors in the prefrontal, parietal and medial temporal cortical regions of post-mortem human schizophrenic brain. Conversely, Gao et al (2000) and others (Kerwin et al, 1990; Kornhuber et $a l, 1989)$ examined glutamate receptor concentrations by radioactive ligand binding and found no significant differences in NMDA receptor levels between schizophrenic and normal tissue. Although in situ hybridization experiments from Jones' laboratory (Akbarian et al, 1996) demonstrated equivalent laminar patterns of NR1 and NR2 transcript expression in both human schizophrenic and control prefrontal cortex, quantitative differences in the levels of NR2 subunit mRNAs were observed. In this region of normal brain, NR2B message is most abundantly expressed, followed by NR2A, NR2D, and NR2C in rank order. However, RNAse protection assays showed a $53 \%$ increase in the levels of NR2D message and a $40 \%$ reduction in NR2C message in schizophrenic prefrontal cortex (Akbarian et al, 1996). Despite these apparent differences in gene expression, the rank-ordered proportional distribution of NMDA receptor subunit levels did not change. In other words, NR2B remained the most abundantly detected subunit, followed by NR2A, NR2D, and NR2C. Finally, Woodruff and Healy (2000) and Akbarian et al (1996) reported elevated NR2B mRNA in schizophrenic hippocampus, and reduced NR1 mRNA in the medial temporal cortex, superior temporal cortex, and frontal cortex. Interestingly, our study using the PCP pharmacological model of NMDA receptor hypofunction demonstrates changes in NMDA receptor subunits that are consistent with alterations noted in human subunit mRNAs between normal and schizophrenic brain (Woodruff and Healy, 2000; Akbarian et al, 1996).

\section{Effects of Chronic PCP Exposure on NMDA Receptor Subunit Proteins}

By immunocytochemistry and immunoblotting, we found regionally specific changes in NMDA receptor subunit expression with minimal changes in AMPA receptor subunit levels. The most significant differences between PCP-treated and control brain involved the obligatory NR1 protein and partnering subunits NR2B, NR2C, and NR2D. Within the frontal cortex specifically, NR1 subunit protein levels were significantly reduced. This result is inconsistent with previous mRNA reports (Wang et al, 1999; Oh et al, 2001) and with immunohistochemistry data from Hanania et al (1999). However, in our laboratory, it was consistently reproducible across all treatment subjects. If verifiable, then a significant discrepancy exists between NR1 gene transcription and downstream events that alter protein availability and, quite possibly, receptor assembly and membrane presentation (ie translation, post-translational modification, protein trafficking, membrane insertion). Protein studies using membrane and cytosolic isolates, rather than whole-cell homogenates, are currently underway to further clarify this disparity. Of the NR2 subunit proteins examined in the prefrontal cortex, NR2B and NR2C were similarly reduced and NR2D was significantly elevated following chronic PCP exposure. Reduced levels of NR2B and NR2C subunit proteins mirror the transcript findings by Linden et al (2001) for the parietal cortex treated with MK801. Our NR2B protein results are also consistent with neonatal changes seen in NR2B mRNA levels in the frontal cortex following chronic postnatal PCP exposure (Sircar et al, 1996). However, they do not reflect either the null change in parietal cortex or the prefrontal cortex decrease in NR2B mRNA following PCP treatment that has been reported previously (Linden et al, 2001; Oh et al, 2001). It is interesting to note that chronic PCP antagonism of the NMDA receptor under our experimental conditions produced minimal, insignificant changes in the NR2A subunit in either the frontal cortex, hippocampus or cerebellum. Again, this conflicts with MK801 transcription data from both Wilson et al (1998) and Oh et al (2001). Of all the information on NR2 subunits cited in the literature, NR2D is perhaps the most obscure. Relatively little is known about its regulation at either the gene level or the protein level. This study demonstrated a significant alteration in the availability of the NR2D subunit following PCP antagonism of the NMDA receptor. Elevated NR2D levels were limited to 
the frontal cortex and did not extend to the hippocampus or cerebellum.

In contrast to the null changes in NR1 message previously seen by Wang et al (1999), we demonstrated enhanced availability of NR1 protein within the CA3 region of the hippocampus as a result of chronic PCP antagonism. While studies detailing the effects of PCP blockage on NR2B and NR2C message in the hippocampus are limited, NR2B and NR2C protein levels declined in our experiments. Finally, the only NMDA receptor subunit protein altered in the cerebellum was NR2B, which decreased dramatically in association with PCP exposure. In comparison, the only antagonist-induced mRNA alteration found by Wang et al (1999) using MK801 involved a decrease in NR2A message.

\section{Effects of Chronic PCP on AMPA Receptor Subunit Proteins}

Initially, one might expect to see minimal changes in the AMPA receptor given that $\mathrm{PCP}$ is a noncompetitive NMDA receptor antagonist. However, the literature is replete with examples of AMPA receptor subunit alterations, resulting from or associated with NMDA receptor manipulation (Malinow and Malenka, 2002), although such changes are primarily limited to receptor trafficking rather than new protein synthesis. Consistent with these findings, it is worth noting that in our experiments, chronic PCP exposure led to a variety of changes in the NMDA receptor without significantly altering most AMPA receptor subunits. Dysfunctional glutamatergic neurotransmission in this case would likely result from changes in NMDA receptor subunit stoichiometry, rather than from abnormalities in AMPA receptor modulation of NMDA receptor function.

\section{Conflicting NR2B Subunit Results}

The immunocytochemistry and Western blot results from our laboratory were conflicting for the NR2B subunit. Immunohistochemistry suggested a reduction in NR2B protein in PCP-treated rat brain, while Western blots consistently showed increases in NR2B levels. This incongruency may be explained by the fact that Western blot analyses measure total cellular levels of protein, while immunocytochemistry measures primarily membrane-localized subunits. Thus, it is possible that more NR2B subunit protein is made in PCP-treated animals, but it is less efficiently inserted into NMDA receptor complexes in the membrane. On the other hand, since the PCP binding site is located on the NR2B subunit, PCP antagonism may actually block the epitopic site recognized by this particular NR2B antibody. This may well explain the reduction in immunolabeling, but would not satisfy as an explanation for the increase in NR2B subunit over control protein levels demonstrated by Western blot.

\section{Interpretation and Implications for Schizophrenia}

Based on the immunocytochemical findings reported here, the relative immunoreactivity of the NR2 receptor subunits in the frontal cortex is altered significantly by chronic PCP exposure (Table 1). Quantitative analysis of the immunohistochemical findings from the control frontal cortex
Table I Relative Distribution of NR2 Subunit Proteins in Control and PCP-Treated Frontal Cortex

Animal group

Frontal cortex group NR2 subunits
Ctrl

PCP
$D>A>C=B$

suggests that NR2B is distributed equally to NR2C, followed by NR2A and NR2D. Following PCP treatment, however, NR2D immunoreactivity and protein expression increase dramatically (266 and $17 \%$, respectively). The relative predominance of immunoreactivity of NR2 subunits in the frontal cortex after PCP exposure places NR2A signal levels behind those of NR2D, followed by NR2C and NR2B, which were approximately equal. Therefore, there appears to be a reversal of NR2 subunit prevalence in the frontal cortex from dominance of NR2B and NR2C in control animals, to dominance of NR2D in PCP-treated animals.

It is tantalizing to speculate that chronic PCP antagonism of the NMDA receptor could pharmacologically regulate regionally specific subunit distribution/expression. These alterations in subunit availability and prevalence could significantly change both the composition and functional characteristics of the NMDA receptor complex. For example, it is reasonable to assume that the reduction in obligatory NR1 protein in the frontal cortex may result in fewer functional NMDA receptor complexes. A reduction in the number of functional NMDA receptors would produce a hypofunctional state in cortical circuits that could ultimately result in excessive glutamate release, loss of inhibitory feedback, and possibly, stereotypic behaviors (Olney et al, 1999). Until recently, the NR3 subunit of the NMDA receptor was not thought to persist beyond developmental stages. Now, in light of its potential role as a substitute obligatory subunit when NR1 is limited and its reputation for suppressing neurotransmission by forming calcium-impermeable channels (Chatterton et al, 2002; Sun et al, 2000; Fukaya et al, 2003; Nishi et al, 2001), studies are underway to examine changes in NR3 subunit proteins following chronic NMDA receptor antagonism.

When considering the changes in the distribution of NR2 subunits, studies have shown that the stoichiometry of receptor subunit assembly affects the kinetics and function of the NMDA channel (Monyer et al, 1994). For example, NR2A or NR2B subunits generate large currents, whereas NR2C or NR2D subunits generate smaller currents (CullCandy et al, 2001). In the present study, we observed a significant shift to predominance of the NR2D subunit in the frontal cortex of PCP-treated rats. NR2D/NR1 containing NMDA receptors have a high affinity for glutamate, relatively slow channel kinetics, and are less sensitive to magnesium blockade than are other subunit assemblies (Monyer et al, 1994; Ikeda et al, 1995; Mishina et al, 1993). Therefore, NR1/NR2D dominance may reflect a compensatory effect in response to the presumed hypoactive state precipitated by chronic PCP antagonism. Altered NMDA receptor subunit assembly may also disrupt ligand-binding sites (eg glutamate, glycine), calcium permeability and sensitivity, receptor complex stability, and intracellular 
signaling cascades. Not only does PCP noncompetitively block the NMDA receptor, it has now been shown to alter pharmacologically NMDA subunit availabilities in specific rat brain regions without significantly affecting AMPA receptor subunits.

There is little known about the role of glutamatergic neurotransmission in thought processing or emotional gating. It is tempting, never the less, to envision a mechanistic role for dysfunctional glutamatergic neurotransmission in a variety of cognitive disorders, particularly schizophrenia. With PCP antagonism of the NMDA receptor strongly linked to dysfunctional glutamatergic neurotransmission, and glutamate-associated neurotoxicity implicated in excitotoxic lesioning, it would not be unreasonable to hypothesize that disruption of NMDA receptor function or performance may contribute to cognitive, memory, and emotional dysfunction. In fact, if NMDA receptor hypofunction is one of the physiological mechanisms that explains PCP psychotic behavior, then it may also play a critical role in the pathophysiology of schizophrenia (Javitt and Zukin, 1991; Duncan et al, 1999; Jentsch and Roth, 1999).

\section{ACKNOWLEDGEMENTS}

This research was supported by National Institute of Mental Health Grant K08 MH64552 to JSL, National Institute of Mental Health Grant MH 58709, and National Center of Research Resources Grant P20 RR15567, which is designated as a Center of Biomedical Research Excellence to JK, and a private internal research grant sponsored by the AVERA McKennan Hospital Association, Sioux Falls, SD to JSL. We thank Robin Miskimins and Ronald Lindahl for comments on the manuscript. Prior to publication, this manuscript received the 2004 APA/Lilly Resident Research Award, presented to JSL.

\section{REFERENCES}

Akbarian S, Sucher N, Bradles D, Tafazzoli A, Trinh D, Heterick P et al (1996). Selective alterations in gene expression for NMDA receptor subunits in prefrontal cortex of schizophrenics. J Neurosci 16: 19-30.

Al-Amin H, Saade N, Khani M, Atweh S, Mohamed J (2003). Effects of chronic dizocilpine on acute pain and on mRNA expression of neuropeptides and the dopamine and glutamate receptors. Brain Res 981: 99-107.

Bernard V, Somogyi P, Bolam JP (1996). Cellular, subcellular and subsynaptic distribution of AMPA-type glutamate receptor subunits in the neostriatum of the rat. J Neurosci 17: 819-833.

Boesch J, Lee C, Lindahl R (1996). Constitutive expression of Class 3 aldehyde dehydrogenase in cultured rat corneal epithelium. J Biol Chem 271: 5150-5157.

Brandoli C, Sanna An, DeBernardi M, Follesa P, Brooker G, Mocchetti I (1998). Brain derived neurotrophic factor and basic fibroblast growth factor downregulate NMDA receptor function in cerebellar granule cells. J Neurosci 18: 7953-7961.

Brose N, Huntley G, Stern-Bach Y, Sharma G, Morrison S, Heinemann S (1994). Differential assembly of coexpressed glutamate receptor subunits in neurons of rat cerebral cortex. J Biol Chem 269: 16780-16784.

Chatterton J, Awobuluyi M, Premkumar L, Takahashi H, Talantova M, Shin Y et al (2002). Excitatory glycine receptors containing the NR3 family of NMDA receptor subunits. Nature 415: 793-798.

Chazot P, Stephenson F (1997). Molecular dissection of native mammalian forebrain NMDA receptors containing the NR1 C2 exon: direct demonstration of NMDA receptors comprising NR1, NR2A and NR2B subunits within the same complex. J Neurochem 69: 2138-2144.

Chen A, McDonald B, Moss S, Gurling H (1998). Gene expression studies of mRNA encoding the NMDA receptor subunits NMDAR1, NMDAR2A, NMDAR2B, NMDAR2C and NMDAR2D following long term treatment with cis- and trans-flupenthixol as a model for understanding the mode of action of schizophrenia drug treatment. Mol Brain Res 54: 92-100.

Corso T, Sesma M, Tenkova T, Der T, Wozniak D, Farber N et al (1997). Multifocal brain damage induced by phencyclidine is augmented by pilocarpine. Brain Res 752: 1-14.

Cull-Candy S, Brickley S, Farrant M (2001). NMDA receptor subunits: diversity, development and disease. Curr Opin Neurobiol 11: 327-335.

Dunah A, Luo J, Wang Y, Yasuda R, Wolfe B (1998). Subunit composition of $N$-methyl-D-aspartate receptors in the central nervous system that contain the NR2D subunit. Mol Pharmacol 53: 429-437.

Duncan G, Zorn S, Lieberman J (1999). Mechanisms of typical and atypical antipsychotic drug action in relation to dopamine and NMDA receptor hypofunction hypothesis of schizophrenia. Mol Psychiatry 4: 418-428.

Fukaya M, Kato A, Lovett C, Tonegawa W, Watanabe M (2003). Retention of NMDA receptor NR2 subunits in the lumen of endoplasmic reticulum in targeted NR1 knockout mice. Proc Natl Acad Sci USA 100: 4855-4860.

Gao X, Sakai K, Roberts R, Conley R, Dean B, Tamminga C (2000). Ionotropic glutamate receptors and expression of $N$-methyl-Daspartate receptor subunits in subregions of human hippocampus: effects of schizophrenia. Am J Psychiatry 157: 1141-1149.

Gao XM, Tamminga CA (1994). An increase in NMDA-sensitive [3H]glutamate and [3H]kainate binding in hippocampus 24 hour after PCP. Neurosci Lett 174: 149-153.

Glover R (2000). Interaction of the $N$-methyl-D-aspartic acid receptor NR2D subunit with the c-Abl tyrosine kinase. J Biol Chem 275: 12725-12729.

Hanania T, Hillman G, Johnson K (1999). Augmentation of locomotor activity by chronic phencyclidine is associated with an increase in striatal NMDA receptor function and an upregulation of the NR1 receptor subunit. Synapse 31: 229-239. Hirsch S, Das I, Garey L, deBelleroche J (1997). A pivotal role for glutamate in the pathogenesis of schizophrenia and its cognitive dysfunction. Pharm Biochem Behavior 56: 797-802.

Hollman M, Heinemann S (1994). Cloned glutamate receptors. Annu Rev Neurosci 17: 31-108.

Horwath Z, Czopf J, Buzsaki G (1997). MK801 induced neuronal damage in rats. Brain Res 753: 181-195.

Huntley G, Vickers J, Morrison J (1994). Cellular and synaptic localization of NMDA and non-NMDA receptor subunits in neocortex: organizational features related to cortical circuitry, function and disease. Trends Neurosci 17: 536-543.

Ikeda K, Araki K, Takayama C, Inoue Y, Yagi T, Aizawa S et al (1995). Reduced spontaneous activity of mice defective in the epsilon 4 subunit of the NMDA receptor channel. Brain Res Mol Brain Res 33: 61-71.

Javitt D, Zukin S (1991). Recent advances in phencyclidine model of schizophrenia. Am J Psychiatry 148: 1301-1308.

Jentsch J, Roth R (1999). The neuropsychopharmacology of phencyclidine: from NMDA receptor hypofunction to the dopamine hypothesis of schizophrenia. Neuropsychopharmacology 20: 201-225.

Khan A, Curras M, Dao J, Jamal F, Turkowski C, Goel R et al (1999). Lateral hypothalamic NMDA receptor subunits NR2A 
and/or NR2B mediate eating: immunochemical/behavioral evidence. Am J Physiol Regul Integr Comp Physiol 276: R880-R891.

Keifer J (2001). In vitro eye-blink classical conditioning is NMDA receptor dependent and involves redistribution of AMPA receptor subunit GluR4. J Neurosci 21: 2434-2441.

Keifer J, Brewer B, Meehan P, Brue R, Clark T (2003). Role for calcindin-D28K in in vitro classical conditioning of abducens nerve responses in turtles. Synapse 49: 106-115.

Kerwin R, Patel S, Medrum B (1990). Quantitative autoradiogrphic analysis of glutamate binding sites on the hippocampal formation in normal and schizophrenic brain post mortem. Neuroscience 39: 25-32.

Kornhuber J, Mack-Burkhardt F, Riederer P, Hebenstreit G, Reynolds G, Andrews $\mathrm{H}$ et al (1989). $\left[{ }^{3} \mathrm{H}\right] \mathrm{MK}-801$ binding items in post mortem brain regions of schizophrenic patients. $J$ Neural Transm 77: 231-236.

Kutsuwada T, Kashiwabuchi N, Sakimurak M, Kushiya E, Araki K, Meguro $\mathrm{H}$ et al (1992). Molecular diversity of the NMDA receptor channel. Nature 358: 36-41.

Lewis D, Lieberman J (2000). Catching up on schizophrenia: natural history and neurobiology. Neuron 91: 415-433.

Linden A, Vasanen J, Storvik M, Lakso M, Korpi E, Wong G et al (2001). Uncompetitive antagonists of the $N$-methyl-D-aspartate (NMDA) receptors alter the mRNA expression of proteins associated with the NMDA receptor complex. Pharmacol Toxicol 88: 98-105.

Malinow R, Malenka R (2002). AMPA receptor trafficking and synaptic plasticity. Annu Rev Neurosci 25: 103-126.

McDonald JW, Johnston MV, Young AB (1990). Differential ontogenic development of three receptors comprising the NMDA receptor/channel complex in the rat hippocampus. Exp Neurol 110: $237-247$.

Mishina M, Mori H, Araki K, Kushiya E, Meguro H, Kutsuwada T et al (1993). Molecular and functional diversity of the NMDA receptor channel. Ann NY Acad Sci 707: 529.

Moghaddam B, Adams B (1998). Reversal of PCP effects by a group II metabotropic glutamate receptor agonist in rats. Science 281: 349-352.

Moghaddam B, Adams B, Verma A, Daly D (1997). Activation of glutamatergic neurotransmission by ketamine: a novel step in the pathway from NMDA receptor blockade to dopaminergic and cognitive disruptions associated with the prefrontal cortex. J Neurosci 17: 2921-2927.

Monyer H, Burnashev N, Laurie D, Sakmann B, Seeburg P (1994). Developmental and regional expression in the rat brain and functional properties of four NMDA receptors. Neuron 12: 529-540.

Morris R, Davis M (1994). The role of NMDA receptors in learning and memory. In Collingridge G, Watkins J (eds) The NMDA Receptor. Oxford University Press: Oxford. p 203.

Murray T, Horita A (1979). Phencyclidine induced stereotyped behavior in rats: dose response effects and antagonism by neuroleptics. Life Sci 24: 2217-2226.

Nishi M, Hinds H, Lu H, Kawata M, Hayashi Y (2001). Motor neuron-specific expression of NR3B, a novel NMDA-type glutamate receptor subunit that works in a dominant-negative manner. J Neurosci 21: RC185.
Oh S, Kim Y, Hann H, Lee H, Choi H, Kim H et al (2001). Modulation of the levels of NMDA receptor subunit mRNA and the bindings of $\left[{ }^{3} \mathrm{H}\right] \mathrm{MK}-801$ in rat brain by chronic infusion of subtoxic dose of MK-801. Neurochem Res 26: 559-565.

Olney J, Farber N (1995). Glutamate receptor dysfunction and schizophrenia. Arch Gen Psychiatry 52: 998-1007.

Olney J, Newcomer J, Farber N (1999). NMDA receptor hypofunction model in schizophrenia. J Psychiatr Res 33: 523-533.

Osten P, Srivastava S, Inman G, Vilim F, Khatri L, Lee L et al (1998). The AMPA receptor GluR2 C terminus can be mediate a reversible, ATP-dependent interaction with NSF and $\alpha$ and $\beta$ SNAPs. Neuron 21: 99-110.

Ouyang Y., Rosenstein A, Kreiman G, Schuman E, Kennedy M (1999). Tetanic stimulation leads to increased accumulation of $\mathrm{Ca}^{2+} /$ calmodulin dependent protein kinase II via dendritic protein synthesis in hippocampal neurons. J Neurosci 19: 7823-7833.

Paxinos G, Watson W (1998). The Rat Brain in Stereotaxic Coordinates. Academic Press: San Diego.

Sassoe-Pognetto M, Ottersen O (2000). Organization of ionotropic glutamate receptors at dendrodendritic synapses in the rat olfactory bulb. J Neurosci 20: 2192-2201.

Scalzo F, Holson R (1992). The ontogeny of behavioral sensitization to phencyclidine. Neurotox Teratol 14: 7-14.

Siegel S, Brose N, Janssen W, Gasic G, Jahn R, Heinemann S et al (1994). Regional, cellular and ultrastructural distribution of $N$ methy-D-aspartate receptor subunit 1 in monkey hippocampus. Proc Natl Acad Sci USA 91: 564-568.

Siegel S, Janssen W, Tullai J, Rogers S, Moran T, Heinemann S et al (1995). Distribution of the excitatory amino acid receptor subunits GluR2(4) in monkey hippocampus and colocalization with subunits GluR5-7 and NMDAR1. J Neurosci 15: 2707-2719.

Sircar R, Chang L (1994). PCP/NMDA receptor channel complex and brain development. Neurotox Teratol 16: 369-375.

Sircar R, Follesa P, Ticku M (1996). Postnatal phencyclidine treatment differentially regulates $N$-methyl-D-aspartate receptor subunit mRNA expression in developing rat cerebral cortex. $\mathrm{Mol}$ Brain Res 40: 214-220.

Sun L, Shipley M, Lidow M (2000). Expression of NR1, NR2A-D and NR3 subunits of the NMDA receptor in the cerebral cortex and olfactory bulb of adult rat. Synapse 35: 212-221.

Wang C, Showalter V, Hillman G, Johnson K (1999). Chronic phencyclidine increases NMDA receptor NR1 subunit mRNA is rat forebrain. J Neurosci Res 55: 762-769.

Watanabe M, Mishina M, Inoue Y (1994). Distinct distributions of five NMDA receptor channel subunit mRNAs in the brainstem. $J$ Comp Neurol 343: 520-531.

Williams K, Dichter MA, Molinoff PB (1992). Up-regulation of $\mathrm{N}$-methyl-D-aspartate receptors on cultured cortical neurons after exposure to antagonists. Mol Pharmacol 42: 147-151.

Wilson M, Kinsman S, Johnston M (1998). Expression of NMDA receptor subunit mRNA after MK-801 treatment in neonatal rats. Dev Brain Res 109: 211-220.

Woodruff J, Healy D (2000). Glutamate receptor expression in schizophrenia brain. Brain Res Rev 31: 280-294.

Yung K (1998). Localization of glutamate receptors in dorsal horn of rat spinal cord. Neuroreport 9: 1639-1644. 